\title{
Long-Term Effect of Corticosteroids on Gardiac Function
}

\author{
Nobuharu Akatsuka, M.D.,* Tetsu Yamaguchi, M.D., \\ and Mitsuo Matsuda, M.D.
}

\begin{abstract}
SUMmary
Q-A2 interval, pre-ejection period and ejection time were calculated from the data of simultaneously recorded ECG, PCG, and external carotid arterial pulse wave in patients with adrenocortical overfunction, namely, Cushing's syndrome and primary aldosteronism, and in patients with nephrotic syndrome or collagen disease under long-term treatments with large doses of glucocorticoids.

PEP/ET ratio, which is considered inversely related to the maximal $\mathrm{dp} / \mathrm{dt}$ of the left ventricle, was markedly increased in the patients with Cushing's syndrome, and in those who were treated with large doses of glucocorticoids for prolonged periods. The PEP/ET ratio in the patients with primary aldosteronism was also increased but not so marked. These results suggest that long-term use of large doses of glucocorticoids impairs the myocardial contractility.
\end{abstract}

\section{Additional Indexing Words :}

Systolic time intervals Cushing's syndrome Primary aldosteronism Glucocorticoid Mineralocorticoid Steroid myopathy Steroid cardiomyopathy

$\mathrm{R}^{\mathrm{B}}$ ECENTLY accumulating clinical evidences indicate some beneficial effects of acute administration of glucocorticoids on the cardiac function in patients with various types of shock. ${ }^{1)}$ Also, the contractility of myocardium has been reported to be augmented by the acute administration of glucocorticoids in isolated papillary muscles of rats. ${ }^{2)}$ Less information, however, is available concerning effects of the long-term administration of large doses of corticosteroids on the cardiac function.

The present work was designed to delineate the effect of the long-term action of large doses of steroid hormone on the cardiac function.

From the First Department of Internal Medicine, Faculty of Medicine, University of Tokyo, 7-3-1, Hongo, Bunkyo-ku, Tokyo, Japan.

* Present address: Department of Physiology and Biophysics, West Virginia University Medical Center, Morgantown, West Virginia 26506, U.S.A.

Received for publication January 21, 1974. 


\section{Methods and Materials}

Electrocardiogram, phonocardiogram and external right carotid arterial pulse wave were simultaneously recorded in the supine position at rest for $10 \mathrm{~min}$. The recordings were obtained at a paper speed of $100 \mathrm{~mm} / \mathrm{sec}$ with a 6 channel recorder (Oscillograph Type 100A, San'ei Instru Ltd, Japan and Model CM-601, Fukuda Electro Co, Japan). Phonocardiograms were recorded at the apex and in the second intercostal space at the left parasternal line with a contact microphone (PGG MIC MA-250, Fukuda Electro Go, Japan). External carotid arterial pulse tracings were recorded with a pulse wave microphone (TY-301, Fukuda Electro Co, Japan).

Systolic time intervals were defined according to the method of Weissler et al. ${ }^{3), 4)}$ The time between the onset of $Q$ wave to the onset of the first high frequency vibration of the aortic component of the second heart sound was designated as Q-A2 interval (Fig. 1). The left ventricular ejection time (ET) was measured from the beginning of the carotid upstroke to the trough of the incisura. The externally measured pre-ejection period (PEP) was calculated by subtracting the left ventricular ejection time from the duration of total electromechanical systole (Q-A2). The

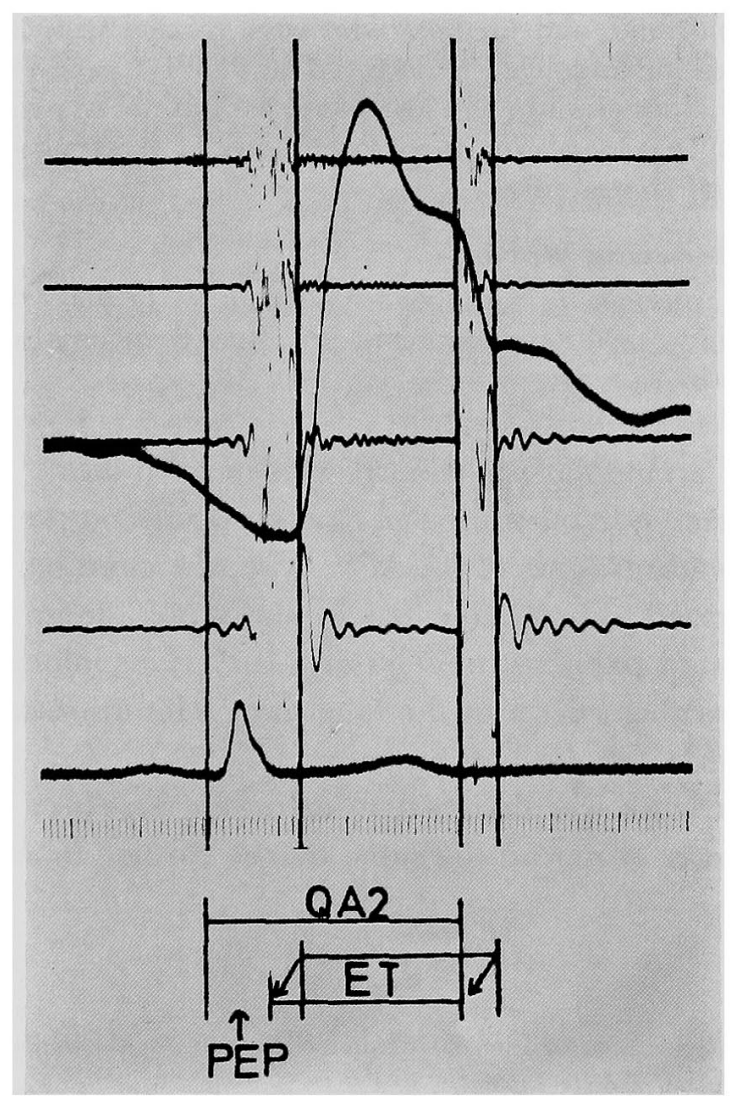

Fig. 1. Simultaneous recording of ECG, PCG, and external carotid arterial pulse wave. Q-A2: total electromechanical systole, ET: left ventricular ejection time, PEP: pre-ejection period $(\mathrm{PEP}=\mathrm{Q}-\mathrm{A} 2-\mathrm{ET})$. 
ratio of PEP to ET was calculated directly from the uncorrected values. In these calculations, correction was not attempted for heart rate.

All intervals were calculated from the mean of measurements made on 10 consecutive beats, each was read to the nearest $5 \mathrm{msec}$.

Four patients with Cushing's syndrome ( 3 females, 1 male, ranging from 33 to 38 years old), 7 with primary aldosteronism ( 4 males, 3 females, ranging from 27 to 39 years old), 7 with nephrotic syndrome without corticosteroid treatments ( 4 males, 3 females, ranging from 18 to 43 years old), 13 with nephrotic syndrome under corticosteroid treatment ( 5 males, 8 females, ranging from 15 to 45 years old), 7 with collagen disease without corticosteroid ( 7 females, ranging from 14 to 43 years old), and 11 with collagen disease under the corticosteroid treatment (11 females, ranging from 14 to 43 years old) were examined (Table I).

Two hundred and seventeen healthy subjects (165 males, 52 females, ranging from 15 to 64 years old) served as the controls.

Four cases which developed overt steroid myopathy, 3 of SLE and 1 of nephrotic syndrome, were separately analyzed (4 females, ranging from 19 to 36 years old).

Average doses and periods of administration of corticosteroid are given in Table II.

Table I. Clinical Diagnoses of Patients

\begin{tabular}{|c|c|c|}
\hline & Cases without steroid & Cases with steroid \\
\hline Cushing's syndrome & 4 & \\
\hline Primary aldosteronism & 7 & \\
\hline Nephrotic syndrome & 7 & 13 \\
\hline Collagen disease & 7 & 11 \\
\hline SLE & 1 & 7 \\
\hline Rheumatic carditis & 2 & 2 \\
\hline Aortitis syndrome & 2 & 1 \\
\hline Scleroderma & 1 & 1 \\
\hline Rheumatoid arthritis & 1 & 0 \\
\hline Steroid myopathy & & 4 \\
\hline SLE & & 3 \\
\hline Nephrotic syndrome & & 1 \\
\hline
\end{tabular}

Table II. Average Doses and Periods of the Administration of Steroid Hormone

\begin{tabular}{l|c|c|c}
\hline & No & $\begin{array}{c}\text { Average doses as predni- } \\
\text { solone mg/day } \pm \text { SD }\end{array}$ & $\begin{array}{c}\text { Average periods } \\
\text { days } \pm \text { SD }\end{array}$ \\
\hline Nephrotic syndrome & 11 & $22.8 \pm 4.0$ & $168 \pm 122$ \\
Collagen disease & 2 & $?$ & 1 year \\
Steroid myopathy & 5 & $32.8 \pm 9.9$ & $101 \pm 27$ \\
& 6 & $?$ & 1 year \\
& 2 & $34.5 \pm 2.5$ & $125 \pm 45$ \\
& 2 & $?$ & 1 year
\end{tabular}


Table III. Summary of Mean PEP/ET Values and Heart Rates in Normal Subjects and in Patient Groups

\begin{tabular}{l|r|r|r|r|r|r}
\hline & \multirow{2}{*}{ No } & \multicolumn{3}{|c|}{ PEP/ET } & \multicolumn{2}{c}{ Heart rate } \\
\cline { 3 - 7 } & & Mean & SD & P values & Mean & SD \\
\hline Normal controls & 217 & 0.234 & 0.045 & & 72.9 & 14.4 \\
Cushing's syndrome & 4 & 0.391 & 0.046 & $0.001^{*}$ & 85.3 & 12.2 \\
Primary aldosteronism & 7 & 0.274 & 0.060 & $0.025^{*}$ & 66.4 & 14.1 \\
Nephrotic syndrome & & & & & & \\
steroid (-) & 7 & 0.265 & 0.048 & $0.01^{*}$ & 84.3 & 9.1 \\
steroid (+) & 13 & 0.348 & 0.060 & $0.01^{*}$ & 92.5 & 16.3 \\
Collagen disease & & & & & & \\
steroid (-) & 7 & 0.295 & 0.044 & $0.001^{*}$ & 97.0 & 4.8 \\
steroid (+) & 11 & 0.345 & 0.098 & $0.05^{*}$ & 89.5 & 13.0 \\
Steroid myopathy & 4 & 0.461 & 0.077 & $0.001^{*}$ & 93.0 & 16.6
\end{tabular}

${ }^{*} \mathbf{P}$ value indicates the significance of the difference between the mean PEP/ET ratio of normal controls and that of patient groups without steroid. $* * \mathrm{P}$ value indicates the significance of the difference between the mean PEP/ET ratios of control patient groups and that of patient groups under steroid regimen.

Table IV. Systolic Intervals and Pertinent Clinical Data in Patients with Cushing's Syndrome, Primary Aldosteronism, and Steroid Myopathy

\begin{tabular}{|c|c|c|c|c|c|c|c|c|c|}
\hline Case & Age & Sex & HR & $\mathrm{BP}$ & $\begin{array}{c}\text { Serum } \\
\mathrm{K}\end{array}$ & PEP/ET & $\begin{array}{l}\text { Q-A2 } \\
\text { (sec) }\end{array}$ & FT (sec) & PFP (sec) \\
\hline \multicolumn{10}{|c|}{ Cushing's syndrome } \\
\hline S.I. & 33 & F & 93 & $170 / 110$ & 5.8 & 0.432 & 0.315 & 0.219 & 0.095 \\
\hline T. N. & 34 & $\mathrm{~F}$ & 83 & $172 / 100$ & 4.4 & 0.429 & 0.321 & 0.224 & 0.096 \\
\hline S.N. & 38 & F & 96 & $168 / 96$ & 3.5 & 0.359 & 0.324 & 0.238 & 0.086 \\
\hline Y. T. & 36 & $\mathbf{M}$ & 69 & $130 / 70$ & 3.1 & 0.344 & 0.367 & 0.273 & 0.094 \\
\hline
\end{tabular}

Primary aldosteronism

\begin{tabular}{llllllllll}
\hline H. T. & 33 & M & 64 & $158 / 108$ & 3.2 & 0.200 & 0.379 & 0.316 & 0.063 \\
B. H. & 36 & M & 64 & $138 / 90$ & 3.4 & 0.237 & 0.397 & 0.321 & 0.076 \\
H. S. & 29 & M & 62 & $160 / 102$ & 2.8 & 0.250 & 0.384 & 0.308 & 0.077 \\
Y. S. & 27 & F & 65 & $150 / 84$ & 3.9 & 0.227 & 0.393 & 0.320 & 0.073 \\
Y. A. & 39 & M & 50 & $180 / 118$ & 2.4 & 0.327 & 0.400 & 0.301 & 0.099 \\
Y. T. & 39 & F & 96 & $208 / 110$ & 1.9 & 0.360 & 0.306 & 0.225 & 0.081 \\
K. S. & 31 & F & 64 & $154 / 94$ & 2.1 & 0.317 & 0.397 & 0.302 & 0.096 \\
\hline
\end{tabular}

Steroid myopathy

$\begin{array}{lllrcccccc}\text { M. T. } & 19 & \text { F } & 77 & 160 / 100 & 4.2 & 0.537 & 0.371 & 0.242 & 0.130 \\ \text { A. O. } & 28 & \text { F } & 103 & 128 / 100 & 4.4 & 0.484 & 0.325 & 0.219 & 0.106 \\ \text { S. N. } & 36 & \text { F } & 81 & 156 / 108 & 3.3 & 0.426 & 0.344 & 0.241 & 0.103 \\ \text { A. Y. } & 27 & \text { F } & 111 & 98 / 74 & 4.1 & 0.395 & 0.293 & 0.210 & 0.085\end{array}$

HR : heart rate, BP : blood pressure, Q-A2 : total electromechanical time, ET : ejection time, PEP : pre-ejection period, TP : total protein. 


\section{RESULTS}

Normal subjects:

In normal subjects, the mean heart rate was $72.9 \pm 14.4$ (mean $\pm \mathrm{SD}$ ). Blood pressure was under $140 \mathrm{mmHg}$ systolic and under $90 \mathrm{mmHg}$ diastolic. The average value of the PEP/ET ratio was $0.234 \pm 0.045$ (Table III).

Cushing's syndrome:

The mean heart rate in patients with Cushing's syndrome was $85.3 \pm$ 12.2. Blood pressures were high both in systolic and diastolic phases. The average value of PEP/ET ratio was $0.391 \pm 0.046$, and was significantly high when compared with normal subjects $(P<0.001$, Tables III and IV, Fig. 2).

Primary aldosteronism:

The mean heart rate in patients with primary aldosteronism was $66.4 \pm$ 14.1. Either systolic or diastolic hypertension or both was found in the blood

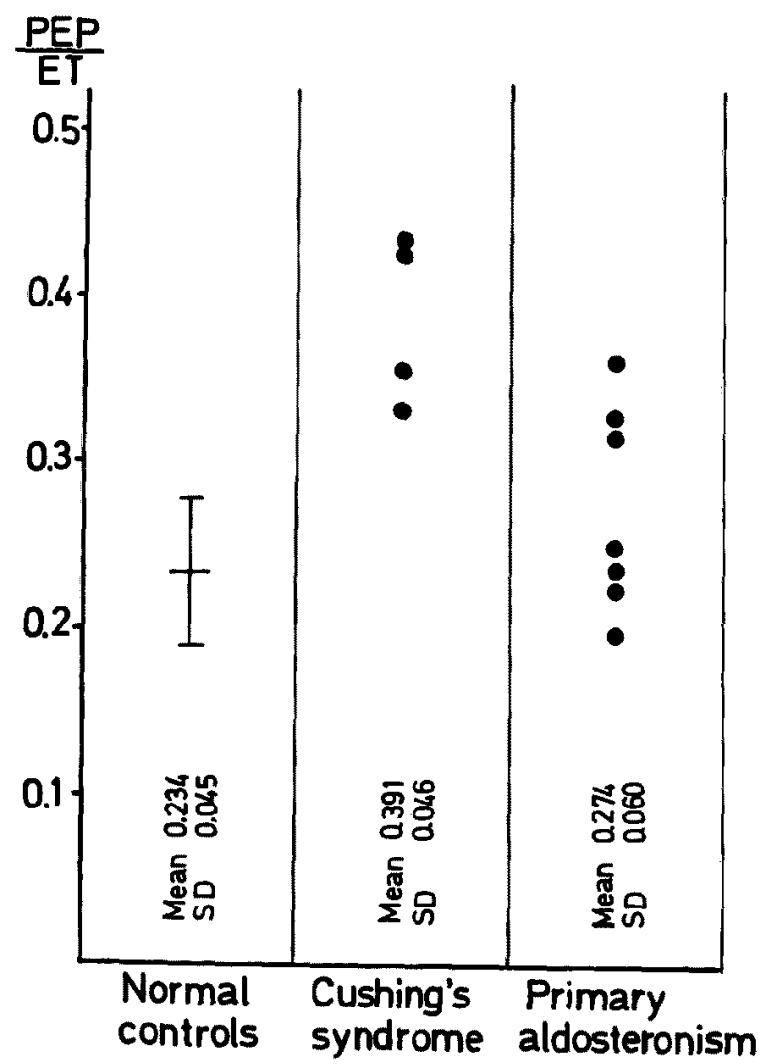

Fig. 2. PEP/ET ratios in Cushing's syndrome and in primary aldosteronism. 
pressure measurements. The average value of the PEP/ET ratio was $0.274 \pm$ 0.060 , and was significantly higher than that of normal subjects $(P<0.025)$, but was significantly low when compared with the value in Cushing's syndrome ( $\mathrm{P}<0.025$, Tables III and IV, Fig. 2).

\section{Nephrotic syndrome:}

Before steroid administration, the mean heart rate in the nephrotic syndrome patient group was $84.3 \pm 9.1$. Blood pressures were within normal range, with the exception of systolic hypertension in 1 patient and diastolic hypertension in 2. The mean $\mathrm{PEP} / \mathrm{ET}$ ratio was $0.265 \pm 0.048$, and was slightly high compared with normal subjects. This difference was statistically significant $(\mathrm{P}<0.01)$.

Table V. Systolic Time Intervals and Pertinent Clinical Data in Patients with Nephrotic Syndrome with and without Steroid Treatment

\begin{tabular}{|c|c|c|c|c|c|c|c|c|c|c|c|}
\hline \multirow[b]{2}{*}{ Case } & \multirow[b]{2}{*}{ Age } & \multirow[b]{2}{*}{ Sex } & \multirow[b]{2}{*}{$\underset{\mathrm{ET}}{\mathrm{PEP} /}$} & \multirow[b]{2}{*}{ HR } & \multirow[b]{2}{*}{$\underset{\text { sec }}{Q-A 2}$} & \multirow[b]{2}{*}{$\begin{array}{l}\text { ET } \\
\text { sec }\end{array}$} & \multirow[b]{2}{*}{$\begin{array}{l}\text { PEP } \\
\sec \end{array}$} & \multirow[b]{2}{*}{ BP } & \multirow{2}{*}{$\begin{array}{c}\text { TP } \\
(\mathrm{Gm} / \\
100 \mathrm{ml})\end{array}$} & \multicolumn{2}{|l|}{ Steroid } \\
\hline & & & & & & & & & & $\begin{array}{l}\text { Total Dose as } \\
\text { Prednisolone (mg) }\end{array}$ & $\begin{array}{r}\text { Period } \\
\text { (days) }\end{array}$ \\
\hline
\end{tabular}

Nephrotic syndrome (Without steroid hormone)

\begin{tabular}{llllllllll}
\hline O. N. & 18 & M & 0.331 & 94 & 0.326 & 0.245 & 0.081 & $148 / 68$ & 4.3 \\
K. N. & 41 & M & 0.242 & 80 & 0.313 & 0.252 & 0.061 & $136 / 82$ & 6.4 \\
A. O. & 43 & F & 0.322 & 79 & 0.356 & 0.269 & 0.087 & $114 / 80$ & 5.4 \\
A. O. & 29 & F & 0.251 & 80 & 0.364 & 0.291 & 0.073 & $102 / 52$ & 6.2 \\
H. I. & 30 & F & 0.221 & 71 & 0.364 & 0.298 & 0.066 & $140 / 100$ & 4.3 \\
N. T. & 23 & M & 0.207 & 91 & 0.325 & 0.269 & 0.056 & $138 / 72$ & 3.7 \\
H. T. & 33 & M & 0.283 & 95 & 0.308 & 0.240 & 0.068 & $130 / 100$ & 6.0
\end{tabular}

Nephrotic syndrome (With steroid hormone)

\begin{tabular}{|c|c|c|c|c|c|c|c|c|c|c|}
\hline O. N. & 18 & $\mathbf{M}$ & 0.395 & 94 & 0.336 & 0.241 & 0.095 & $150 / 88$ & 2,400 & 100 days \\
\hline K. M. & 23 & $\mathbf{M}$ & 0.492 & 111 & 0.320 & 0.215 & 0.106 & $120 / 64$ & 600 & 30 days \\
\hline K. N. & 41 & $\mathbf{M}$ & 0.347 & 80 & 0.350 & 0.260 & 0.090 & $138 / 80$ & 1,400 & 50 days \\
\hline K. N. & 15 & $\mathbf{M}$ & 0.302 & 102 & 0.289 & 0.222 & 0.067 & $140 / 80$ & 2,100 & 100 days \\
\hline K. U. & 24 & $\mathbf{M}$ & 0.326 & 61 & 0.358 & 0.270 & 0.088 & - & Large & 1 year \\
\hline Y. S. & 30 & $\mathrm{~F}$ & 0.295 & 92 & 0.330 & 0.255 & 0.075 & $130 / 80$ & 1,500 & 80 days \\
\hline T. T. & 24 & $\mathbf{F}$ & 0.302 & 101 & 0.329 & 0.252 & 0.076 & $120 / 70$ & 1,500 & 80 days \\
\hline R. A. & 34 & $\mathbf{F}$ & 0.344 & 94 & 0.326 & 0.243 & 0.084 & $130 / 90$ & 9,400 & 400 days \\
\hline A. 0 . & 43 & $\mathbf{F}$ & 0.327 & 88 & 0.351 & 0.265 & 0.087 & $135 / 80$ & 1,900 & 100 days \\
\hline A. Y. & 27 & $F$ & 0.375 & 98 & 0.338 & 0.246 & 0.092 & $108 / 58$ & 5,400 & 170 days \\
\hline S. S. & 30 & $\mathrm{~F}$ & 0.290 & 81 & 0.368 & 0.285 & 0.083 & $116 / 78$ & 2,000 & 100 days \\
\hline Y. T. & 45 & $\mathrm{~F}$ & 0.303 & 125 & 0.288 & 0.221 & 0.067 & - & 9,400 & 390 days \\
\hline $\mathbf{M}, \mathbf{K}$. & 18 & $\mathrm{~F}$ & 0.426 & 75 & 0.395 & 0.277 & 0.118 & - & 6,000 & 280 days \\
\hline
\end{tabular}




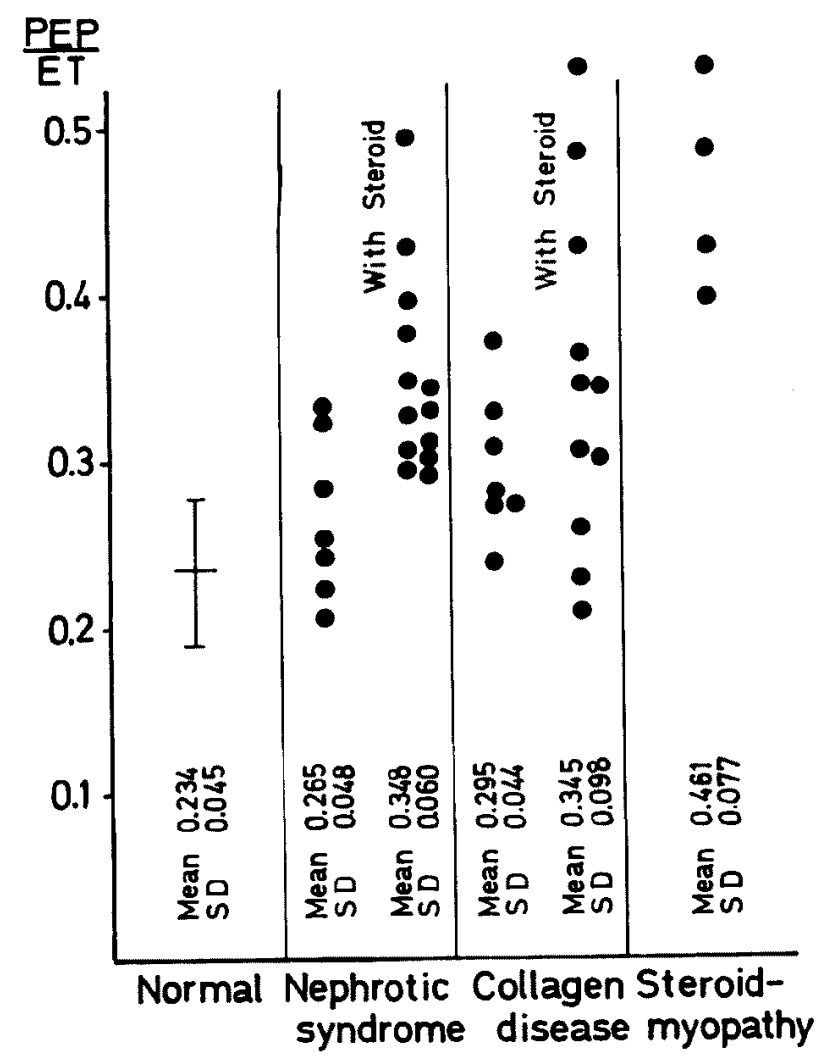

Fig. 3. PEP/ET ratios of control groups and steroid treated groups in nephrotic syndrome and collagen disease, and the ratios in steroid myopathy.

Following the treatment with corticosteroids, an increased mean heart rate $(92.5 \pm 16.3)$ was observed. Blood pressures were normal in most cases. The mean $\mathrm{PEP} / \mathrm{ET}$ ratio was $0.348 \pm 0.060$, which was a significant increase in the ratio ( $\mathrm{P}<0.01$, Tables III and V, Fig. 3).

\section{Collagen disease:}

Before corticosteroid treatment, the heart rate was already accelerated $(97.0 \pm 4.8)$. Blood pressures were variable. The mean PEP/ET ratio was $0.295 \pm 0.044$, and was significantly higher than that of the normal subjects $(\mathrm{P}<0.001)$.

During the administration of corticosteroids, the mean heart rate was $89.5 \pm 13.0$, showing slight decrease in the heart rate when compared with that in the control period. The mean PEP/ET ratio $(0.345 \pm 0.098)$ was significantly increased above the value in the control period $(P<0.05$, Tables III and VI, Fig. 3). 
Table VI. Systolic Time Intervals and Pertinent Clinical Data in Patients with Collagen Disease with and without Steroid Treatment

\begin{tabular}{|c|c|c|c|c|c|c|c|c|c|c|}
\hline \multirow[b]{2}{*}{ Case } & \multirow[b]{2}{*}{ Age } & \multirow[b]{2}{*}{ Sex } & \multirow[b]{2}{*}{$\underset{\mathrm{ET} /}{\mathrm{PEP} /}$} & \multirow[b]{2}{*}{ HR } & \multirow[b]{2}{*}{$\begin{array}{c}\text { Q-A2 } \\
\text { sec }\end{array}$} & \multirow[b]{2}{*}{$\begin{array}{l}\text { ET } \\
\text { sec }\end{array}$} & \multirow[b]{2}{*}{$\underset{\sec }{\mathrm{PEP}}$} & \multirow[b]{2}{*}{$\mathrm{BP}$} & \multicolumn{2}{|c|}{ Steroid } \\
\hline & & & & & & & & & $\begin{array}{l}\text { Total Dose } \\
\text { as Predniso- } \\
\text { lone (mg) }\end{array}$ & $\begin{array}{l}\text { Period } \\
\text { (days) }\end{array}$ \\
\hline \multicolumn{11}{|c|}{ Collagen disease (Without steroid hormone) } \\
\hline $\begin{array}{l}\text { S.M. } \\
\text { (Aortitis syndrome) }\end{array}$ & 43 & $\mathbf{F}$ & 0.239 & 111 & 0.330 & 0.266 & 0.064 & $170 / 80$ & & \\
\hline $\begin{array}{l}\text { S. S. } \\
\text { (Rheumatic carditis) }\end{array}$ & 14 & $\mathbf{F}$ & 0.276 & 97 & 0.333 & 0.261 & 0.072 & $108 / 40$ & & \\
\hline $\begin{array}{l}\text { K. N. } \\
\text { (Rheumatic carditis) }\end{array}$ & 16 & $\mathbf{F}$ & 0.306 & 111 & 0.290 & 0.222 & 0.068 & $120 / 70$ & & \\
\hline $\begin{array}{l}\text { A. O. } \\
\text { (SLE) }\end{array}$ & 28 & $\mathrm{~F}$ & 0.370 & 114 & 0.296 & 0.216 & 0.080 & $148 / 94$ & & \\
\hline $\begin{array}{l}\text { T. S. (Scleroderma- } \\
\text { tomyositis) }\end{array}$ & 40 & $\mathrm{~F}$ & 0.328 & 74 & 0.403 & 0.303 & 0.100 & $102 / 72$ & & \\
\hline $\begin{array}{l}\text { K. K. } \\
\text { (Rheumatic arthritis) }\end{array}$ & 34 & $\mathbf{F}$ & 0.272 & 86 & 0.337 & 0.265 & 0.072 & $120 / 72$ & & \\
\hline $\begin{array}{l}\text { M. I } \\
\text { (Aortitis syndrome) }\end{array}$ & 40 & $\mathrm{~F}$ & 0.272 & 86 & 0.368 & 0.301 & 0.067 & $150 / 80$ & & \\
\hline \multicolumn{11}{|c|}{ Collagen disease (With steroid hormone) } \\
\hline $\begin{array}{l}\text { M. T. } \\
\text { (SLE) }\end{array}$ & 19 & $\mathbf{F}$ & 0.537 & 77 & 0.371 & 0.242 & 0.130 & $160 / 100$ & Large & Long \\
\hline $\begin{array}{l}\text { M. M. } \\
\text { (Scleroderma) }\end{array}$ & 25 & $\mathbf{F}$ & 0.362 & 99 & 0.315 & 0.231 & 0.084 & $106 / 64$ & 7,000 & 150 days \\
\hline $\begin{array}{l}\text { S.M. } \\
\text { (Aortitis syndrome) }\end{array}$ & 43 & $\mathbf{F}$ & 0.257 & 112 & 0.332 & 0.265 & 0.068 & $140 / 70$ & 1,200 & 70 days \\
\hline $\begin{array}{l}\text { S. S. } \\
\text { (SLE) }\end{array}$ & 16 & $\mathbf{F}$ & 0.300 & 78 & 0.329 & 0.253 & 0.076 & $110 / 70$ & Large & Long \\
\hline $\begin{array}{l}\text { S. S. } \\
\text { (Rheumatic carditis) }\end{array}$ & 14 & $\mathbf{F}$ & 0.343 & 100 & 0.348 & 0.259 & 0.089 & $124 / 50$ & 3,300 & 100 days \\
\hline $\begin{array}{l}\text { A. O. } \\
\text { (SLE) }\end{array}$ & 28 & F & 0.484 & 103 & 0.325 & 0.219 & 0.106 & $128 / 80$ & 2,950 & 80 days \\
\hline $\begin{array}{l}\text { S. N. } \\
(\text { SLE) }\end{array}$ & 36 & F & 0.426 & 81 & 0.344 & 0.241 & 0.103 & $156 / 108$ & Large & 3 years \\
\hline $\begin{array}{l}\text { M. K. } \\
\text { (SLE) }\end{array}$ & 35 & F & 0.228 & 91 & 0.327 & 0.266 & 0.061 & $156 / 106$ & 27,000 & 5 years \\
\hline$\underset{(S L E)}{J}$ & 23 & $\mathbf{F}$ & 0.304 & 77 & 0.359 & 0.275 & 0.084 & $138 / 76$ & 18,000 & 3 years \\
\hline $\begin{array}{l}\text { Y. K. } \\
\text { (SLE) }\end{array}$ & 26 & F & 0.209 & 73 & 0.369 & 0.305 & 0.064 & $124 / 76$ & 2,500 & 240 days \\
\hline $\begin{array}{l}\text { K. N. } \\
\text { (Rheumatic carditis) }\end{array}$ & 16 & $\mathbf{F}$ & 0.343 & 93 & 0.348 & 0.259 & 0.089 & $110 / 70$ & 3,300 & 100 days \\
\hline
\end{tabular}

\section{Steroid myopathy:}

The mean heart rate was $93.0 \pm 16.6$. Three patients had slight diastolic hypertension. The mean PEP/ET ratio was $0.461 \pm 0.077$, and was remarkably high (Tables III and IV, Fig. 3). 

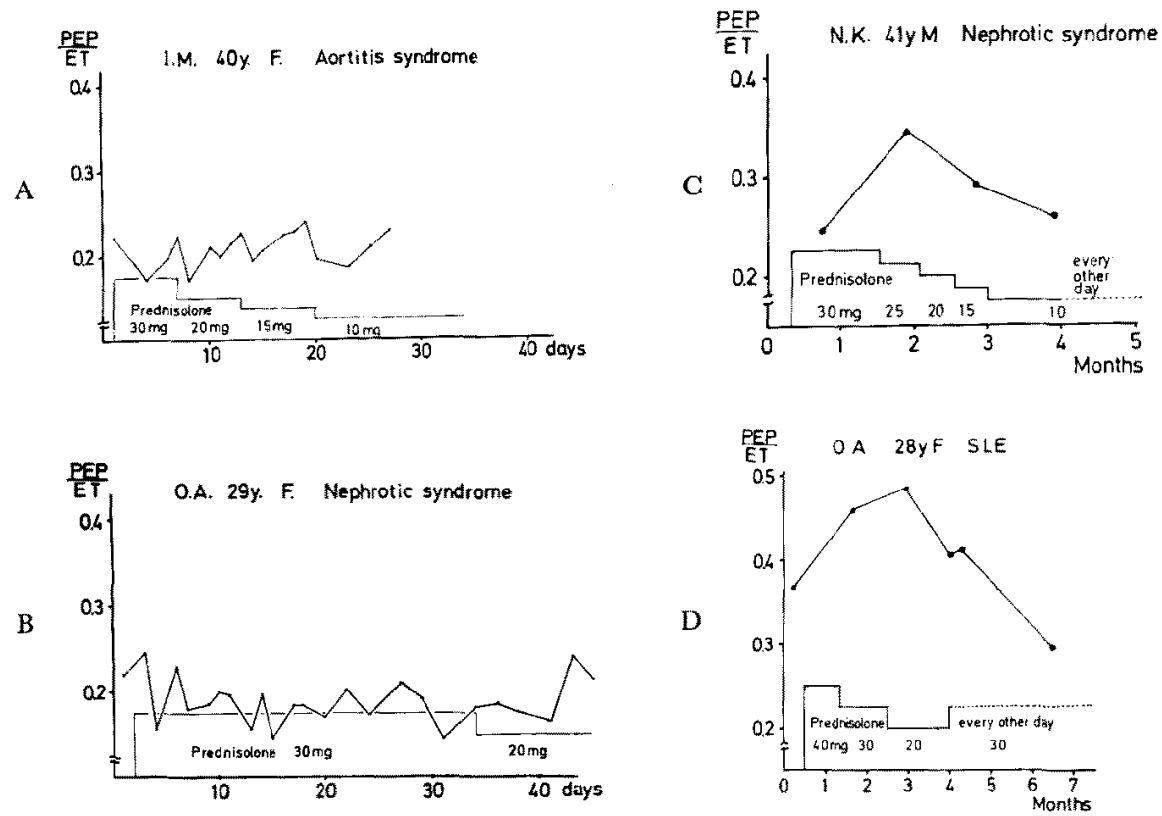

Fig. 4. Changes in PEP/ET ratio during the early phase of steriod treatment. A: aortitis syndrome, B: nephrotic syndrome, $C$ : nephrotic syndrome, D: SLE.

The early phase of the treatment with large doses of glucocorticoids:

Some examples of the course of the PEP/ET ratios in patients with aortitis syndrome, SLE and nephrotic syndrome are shown in Fig. 4A to D. The changes in the PEP/ET ratios were variable in the initial phase of the treatment with large doses of glucocorticoid.

\section{Discussion}

Simultaneous recording of ECG, PCG and external carotid arterial pulse wave has been widely used as a noninvasive and valuable approach to the study of cardiac performance in the clinical field. This technic has such the advantage of allowing repeated evaluations without any harm to the patients. In this study, this approach was applied to examine the effect of steroids on systolic time intervals. There seems to be general agreement that the ratio of pre-ejection period to ventricular ejection time is inversely related to the maximal rate of pressure development of the left ventricle ( $\max \mathrm{dp} / \mathrm{dt}$ ), which apparently reflects alteration in the myocardial contractility. ${ }^{5)}$ The ratio of PEP/ET decreases in hyperactive states such as hyperthyroidism, and mental and physical excitement, whereas it increases with impaired myo- 
cardial contractility, for instance, in hypothyroidism and in congestive heart failure. In addition, the PEP/ET ratio, without correction for heart rate and sex, varies within narrow limits. Thus, the PEP/ET ratio may afford a convenient evaluation of myocardial contractility." In the present study, we calculated the PEP/ET ratio as a reliable indicator of the myocardial contractility.

Significant increase in the PEP/ET ratio was observed in Cushing's syndrome, and in primary aldosteronism (Fig. 2). The increased PEP/ET ratio suggests impaired myocardial contractility in these groups. Plotz and his coworkers $^{6}$ ) found that in about $30 \%$ of the fatal cases with Cushing's syndrome, the cause of death was congestive heart failure, which results from hypertension or from electrolyte imbalance.

Systolic time intervals are affected by arterial blood pressure acting as an afterload. Hypertension, especially diastolic, is the common feature of these 2 groups with significantly increased PEP/ET ratios. However, the increase in PEP/ET ratio in the elderly group with diastolic hypertension is usually only moderate. ${ }^{\dagger}$ Therefore, hypertension is not considered to be the main factor in the increase of the PEP/ET ratio in these 2 groups.

The serum potassium concentration was almost within normal limits in Cushing's syndrome, but it was markedly low or almost below the normal range in primary aldosteronism. It is well known that hypopotassemia may cause myocardial as well as skeletal muscle necrosis. It would be reasonable to expect the most remarkable change in the PEP/ET ratio in primary aldosteronism with marked hypopotassemia. However, the increase in PEP/ET ratio in primary aldosteronism was not greater than the increase in Cushing's syndrome, which had nearly normal serum potassium concentrations. Therefore, the increase in PEP/ET ratio in these cases is not the effect of hypopotassemia alone.

A more attractive explanation for the increment in the PEP/ET ratio in patients with Cushing's syndrome appears to be that it may be not due to the effect of mineralocorticoids, but due to that of glucocorticoids. To examine this speculation, we measured the PEP/ET ratio in patients with various diseases, who were administered large doses of glucocorticoids for prolonged periods. Although patients with nephrotic syndrome or with collagen disease had slightly but significantly high control values of PEP/ET ratio, the ratio exhibited a marked increase with a large dosage treatment of the steroids.

† Normal controls: $165,0.233 \pm 0.048$ (cases, mean PEP/ET ratio $\pm S D$ ); Systolic ( $\geqq 150 \mathrm{mmHg}$ ) and diastolic ( $\geqq 90 \mathrm{mmHg}$ ) hypertension: $60,0.267 \pm 0.064$; Systolic hypertension ( $\geqq 150 \mathrm{mmHg}$ ): $53,0.257 \pm 0.050$; Diastolic hypertension $(\geqq 90 \mathrm{mmHg}$ ): $34,0.270 \pm 0.064$. All were males over 30 years old (our unpublished data). 
Especially in the patients who developed steroid myopathy, the increase in the ratio was quite remarkable. In these patients with steroid myopathy, hypopotassemia was not noted, and the blood pressure was almost identical to the value in Cushing's syndrome and in primary aldosteronism. Thus, it is likely that not only myopathy of the skeletal muscles but also cardiomyopathy may be induced by the prolonged administration of large doses of glucocorticoids.

The acute pharmacological effect of glucocorticoids on myocardial contractility is said to be enhancing in vivo and in vitro. ${ }^{1), 2)}$ However, as the pharmacological effect of steroid hormones on the PEP/ET ratio is variable as shown in the previous figures (Fig. $4 \mathrm{~A}$ to D), it can be said that there is no consistent change in the PEP/ET ratio during the early phase of treatment.

Therefore, the apparent impairment of myocardial contractility, seen after prolonged administration of corticosteroids, might have been due to the myocardial changes induced by the hormone.

It is also well known that in Cushing's syndrome organic vascular changes such as wide spread degenerative change and extensive thrombonecrosis of arterioles $^{7 /}$ may occur. However, the increased PEP/ET ratio in patients under steroid treatment is restored to normal after discontinuing treatment. Therefore, it is reasonable to think that the cause of increase in PEP/ET ratio in these patients may not be due to irreversible histological changes in coronary artery induced by the chronic administration of glucocorticoids.

In nephrotic syndrome and in collagen disease, the diseases themselves may serve as a main factor impairing myocardial contractility. Certainly, the ratios were increased already at the beginning of the corticosteroid treatments in these cases, but the ratio increased more with treatments in spite of improvement of the diseases. This increase must be the effect of steroid treatment, and is not due to cardiac involvement of the basic disease.

Although the patients treated with large doses of corticosteroids did not exhibit any clinical evidence of either congestive heart failure or deteriorated cardiac function other than modest sinus tachycardia during follow-up period, the increased PEP/ET ratio may represent the state of impaired myocardial contractility.

It has been widely accepted that the myocardium does not show any remarkable morphological changes in light microscopic finding following steroid treatments. ${ }^{8)}$ However, this conclusion was based on the relatively short-termed observation. Although a recent electron microscopic and histochemical observation on myocardium under the effect of glucocorticoid revealed some changes such as atrophic myofibrils, structural changes in mitochondria and increase in glycogen granules, ${ }^{9}$ it needs further research 
to elucidate a relationship of functional alterations as observed in the present work to some morphological or biochemical changes.

\section{ACKNOWLEDGEMENTS}

The authors would like to acknowledge the invaluable suggestions of Prof. Y. Yoshitoshi, Dr. N. Honda, Dr. E. Ogata, and Prof. M. F. Wilson, and also would like to express their sincere thanks to Mrs. M. Fukubayashi and Miss M. Yoshikane for secretarial aids.

\section{REFERENCES}

1. Sambhi MP, Weil MH, Udhoji VN: Acute pharmacodynamic effects of glucocorticoids: Cardiac output and related hemodynamic changes in normal subjects and patients in shock. Girculation 31: 523, 1965

2. Lefer AM: Influence of corticosteroids on mechanical performance of isolated rat papillary muscles. Am J Physiol 214: 518, 1968

3. Weissler AM, Harris WS, Schoenfeld CD: Systolic time intervals in heart failure in man. Circulation 37: 149, 1968

4. Weissler AM, Harris WS, Schoenfeld CD: Bedside technics for the evaluation of ventricular function in man. Am J Cardiol 23: 577, 1969

5. Martin CE, Shaver JA, Thompson ME, Reddy PS, Leonard JJ : Iirect correlation of external systolic time indices of left ventricular function in man. Circulation 44: 419, 1971

6. Plotz GM, Knowlton AI, Ragan G: The natural history of Cushing's syndrome. Am J Med 13: 597, 1952

7. Scholz DA, Sprague RG, Kernohan JW： Cardiovascular and renal complications of Cushing's syndrome. A clinical and pathological study of seventeen cases. New Eng J Med 256: 833, 1957

8. Ellis JT: Studies on the nature and pathogenesis of muscular degeneration in cortisone treated rabbits. Bull NY Acad Sc 29: 814, 1953

9. Tsukahara Y: An enzyme histochemical and electron microscopic study on steroid cardiomyopathy in rabbit. Med J Shinshu Univ 14: 123, 1969 